\title{
Feedback from the readers: what you have told us
}

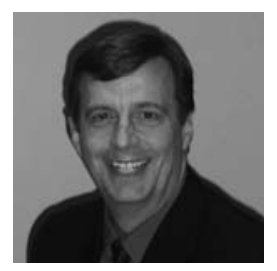

James Ducharme, MD

Version fRANÇAISE À la page 8

$\mathrm{I}^{\mathrm{n}}$ $\mathrm{n}$ the summer of 2007 , the new senior editorial board at CJEM felt it was essential to obtain input from its various decision and section editors and, more importantly, from you, its readers. This input was to be used as the starting point for planning any potential changes to CJEM. While we had some ideas about change, as evidenced by the directed questions, we were hoping to obtain abundant commentary in the open-ended question: what would you like to see changed?

In the past, CAEP surveys have taught us that CJEM is an important reason for many physicians to be CAEP members, so while we were gratified with your strong response to our survey (296 responses), we were not surprised. From your answers we have learned the following:

1. Canadian content. There was a strong desire to see CJEM maintain a focus on Canadian emergency medicine. Many of you were concerned that, with indexing, we would become "just another venue for publications." Some of you suggested that if articles from other countries were to be published, they should have direct pertinence to Canadian physicians. A common theme in the comments section was a request for news and discussion about people and events within emergency medicine in Canada. This would seem to be best served with a CAEP newsletter, perhaps distributed at the same time as CJEM. We have brought this request forward to the CAEP Head Office.

2. Electronic version. Far fewer of you than expected showed interest in receiving an electronic version in PDFformat via email or as a podcast. Most of you seemed satisfied with CJEM's current format. There was some interest in an electronic version, so we will look further into that possibility. We will continue to monitor this as the electronic generation replaces the "paper" one.
3. Branding. Many of you felt the cover and style are "getting old." We agree. CAEP and CJEM are currently reviewing CJEM's branding and as part of that, we are exploring the options for a new style for both the journal and the website.

4. Editorials. There was a very strong expression of interest in having regular editorials that discuss controversies in emergency medicine. We hope you have noticed that every issue since last summer has included such articles. We hope to maintain this practice well into the future. While some of you felt that editorials should not have a political tone - given this is a medical journal - we feel it is almost impossible to separate medicine from politics. However, in addition to political themes, we will endeavour to publish editorials that reflect controversies in treatment or commentaries about specific articles that we publish.

5. Methodology. It was almost unanimous: people want to see 1-page methodology summaries related to articles published in CJEM. The editorial board will attempt to publish 3 such papers per year, discussing the methodology used in an article published in the same issue.

6. Areas of focus. The Editorial Advisory Board have agreed that medical education is a strength in Canadian academic emergency medicine and that we should increase publications in that area. Many of you indicated that you would like to see articles related to medicolegal issues as well as general reviews on specific topics. CJEM has always encouraged submission of systematic reviews, as narrative reviews tend to be less objective. We will continue to encourage submissions of papers in these domains, but recognize that we are at the mercy of the willingness of authors to produce such work. 
After receiving such a strong response from CJEM's readers, we are now asking for involvement and feedback from residency directors and academic leaders from across the country to be ever more involved with $C J E M$, with the hope that CJEM will be their first choice for publication.

While we have heard clearly the desire for change and growth, we have also heard an equally strong message most of you are very happy with CJEM just as it is. We will tread carefully as we make changes: we at CJEM also love the journal as it is. We have no desire to damage what
Grant Innes and others worked so hard to create. As we consider steps forward, we will continue to ask for your input - the journal is for Canadian emergency physicians, not for its editors.

Thank you for having responded. We hope it will always be the case that the readers guide CJEM's direction, while the editors simply "make it so."

Correspondence to: cjem@caep.ca 